\title{
Development of population structure in Daphnia clones in a stratified lake
}

\author{
MARVIN JON ROSS*†, JAMES W. CURTSINGER $\ddagger$ \& ROBERT O. MEGARD $\ddagger$ \\ †University of Minnesota, Lake Itasca Biological Station, HC 05 Box 7, Lake Itasca, Minnesota 56460 and $\ddagger$ University \\ of Minnesota, Department of Ecology, Evolution and Behavior, 100 Ecology Building, 1987 Upper Buford Circle, St. \\ Paul, Minnesota 55108, U.S.A.
}

\begin{abstract}
The frequencies of single locus genotypes (clones) in a natural population of Daphnia pulicaria in a Minnesota lake were estimated during five months when the lake was thermally stratified in 1991. Further samples were collected in early August 1990 and 1992. Daphnia pulicaria were aggregated during daytime in two layers detected with high-frequency sonar. One layer was in the metalimnion and upper hypolimnion (depth 10-15 m), the other deeper in the hypolimnion (18-22 m). The layers were sampled at two locations in Long Lake on eight dates in 1991. Cellulose acetate electrophoresis revealed four alleles at the phosphoglucose isomerase $(P G I)$ locus. Three clones occurred with sufficient frequency in 3077 individuals for statistical analysis. The proportion of homozygous slow $(S S)$ individuals increased with time in the deep layer at both locations, coincident with decreasing concentrations of dissolved oxygen, but was nearly constant in the shallower layer, where oxygen was near saturation. Analysis with log-linear statistics indicated that depth, date and the depth-date interaction were most important in explaining the variations in clone proportions during summer. Location and the date-location interaction, although significant, were less important. Data from early August 1990 and 1992 indicated that this pattern may be an annual phenomenon.
\end{abstract}

Keywords: Daphnia pulicaria, electrophoresis, hydroacoustic, log-linear modelling, population structure.

\section{Introduction}

Spatially and temporally fluctuating selection have been invoked to explain genetic diversity and clonal coexistence in cladoceran populations that reproduce parthenogenetically for protracted periods (Hebert, 1978; Lynch, 1984; Weider, 1985). Because Cladocera reproduce by ameiotic parthenogenesis during most of the year, selection operates on specific genotypes for repeated generations (Lynch, 1983). As Young (1979b) noted, all the members of a clone from the first ex-ephippial female to her last surviving clonal descendent constitute the extended soma of a single genetic individual. A clone may persist through several seasonal or even annual cycles in permanent populations. Because the average lifetime of a clone is much longer than a single individual, subtle environmental effects may be more readily observed.

\footnotetext{
*Correspondence
}

The spatial distribution of clones in the genus Daphnia has been studied extensively. Substantial differences in clone composition have been observed both among ponds in the same geographical area (Hebert \& Crease, 1980; Weider \& Hebert, 1987a; Weider, 1989) and within individual lakes and ponds (Weider, 1984, 1985, 1989). Spatial patterns of clone composition have been observed (Weider \& Hebert, 1987a) and ascribed to environmental variation such as salinity/conductivity gradients (Weider \& Hebert, 1987b), and dissolved oxygen (Weider \& Lampert, 1985).

Beginning with Hebert's (1974) observation of drastic temporal shifts in genotypic frequencies of $D$. magna, many authors have observed significant temporal changes within ponds and lakes in the clonal composition of permanent populations of Daphnia (Hebert \& Ward, 1976; Young, 1979a; Weider, 1984, 1985; Mort \& Wolf, 1985; Jacobs, 1990; Muller \& Seitz, 1993). However, an underlying pattern to these temporal shifts remains elusive. With the exception of Hebert \& Ward (1976) and 
Young (1979a), the aforementioned studies were conducted in relatively deep bodies of water ranging from 6 to $60 \mathrm{~m}$ in maximum depth. Carvalho \& Crisp (1987) and Carvalho (1987), working in a much shallower environment $(1.2 \mathrm{~m}$ max. depth, $0.6 \mathrm{~m}$ mean depth), were the first to provide an example of clear seasonal patterns of clone frequencies in D. magna correlated with seasonal changes in water temperature.

Weider (1985) pointed out that the planktonic habitat in deeper lakes and ponds is much more structured than previously thought, especially in the vertical dimension. Results from Weider (1984, 1985 ) with $D$. pulex in a seasonally stratified pond only $6 \mathrm{~m}$ deep suggest that the genetic structure of planktonic cladoceran populations also may be more complex spatially (both vertically and horizontally) and temporally than previously thought within individual ponds and lakes. Temporal patterns of clonal succession could be complicated by significant spatial differences within lakes, especially in deeper basins.

Here, we examine spatial and temporal distributions of clones of pelagic $D$. pulicaria in a vertically stratified, single basin, freshwater lake. Daphnia pulicaria dominates the $D$. pulex complex in North American lakes (Cerny \& Hebert, 1993).

Carvalho \& Crisp (1987) and Weider (1989) demonstrated the need to use relatively sophisticated analytical techniques to describe the effects of interacting variables on the frequency of Daphnia clones. Many previous studies have limited analyses to pairwise observations of clone frequency and either spatial or temporal explanatory variables. Here we used a four dimensional log-linear approach to analyse how clone frequency, the response variable, was related to horizontal location, depth, and time, and to analyse more complex second- and third-order interactions with this group of explanatory variables.

\section{Study area}

Long Lake (Fig. 1), located in Clearwater County in north-western Minnesota (latitude $47^{\circ} 17^{\prime} \mathrm{N}$, longitude $95^{\circ} 17^{\prime} \mathrm{W}$ ), is $2.3 \mathrm{~km}$ long from north-west to south-east, with an average width of $0.4 \mathrm{~km}$., a surface area of 66.5 hectares and a maximum depth of $24 \mathrm{~m}$. The lake is very clear compared to other lakes in the region, with Secchi transparency up to $10.5 \mathrm{~m}$ (Moyle, 1969). The lake basin is characterized by extremely steep slopes. The basin shape combined with rocky substrate in the littoral zone results in virtually no emergent aquatic vegetation.
Submergent vegetation comprised principally of Chara contraria is relatively abundant especially on the south-west facing slope (Schmid, 1965). Limnologically, the lake is dimictic (mixing throughout the water column in spring and autumn). It is high in carbonates and is in the mesotrophic to oligotrophic range of freshwater productivity (Megard, 1967, 1968; Moyle, 1969). Thermal stratification results in depleted levels of dissolved oxygen below $15 \mathrm{~m}$ especially during summer and early autumn.

\section{Materials and methods}

The spatial distribution of zooplankton was discerned with a high frequency $(192 \mathrm{kHz})$ sonar system that consisted of a Lowrance Xl6 graph type echolocator coupled to a modified microcomputer (Megard et al., 1989; Megard et al., in prep.). Backscattering of high frequency sound was measured along transects on the lake. Specific sampling sites were selected based on an initial lengthwise acoustic transect each day that collections were made. Two sites were selected and acoustic cross-sections (short axis of the lake) were obtained. Site selection was based upon a combination of two criteria: the first was the appearance of discrete depth layers of zooplankton on the computer monitor and the second was the need to maintain a relatively large distance between sampling sites. Sampling areas are indicated in Fig. 1. Previous experience had indicated that zooplankton could form mobile aggregations, therefore we used acoustic information to select specific sampling sites and depths each day within the confines of the general sampling areas.

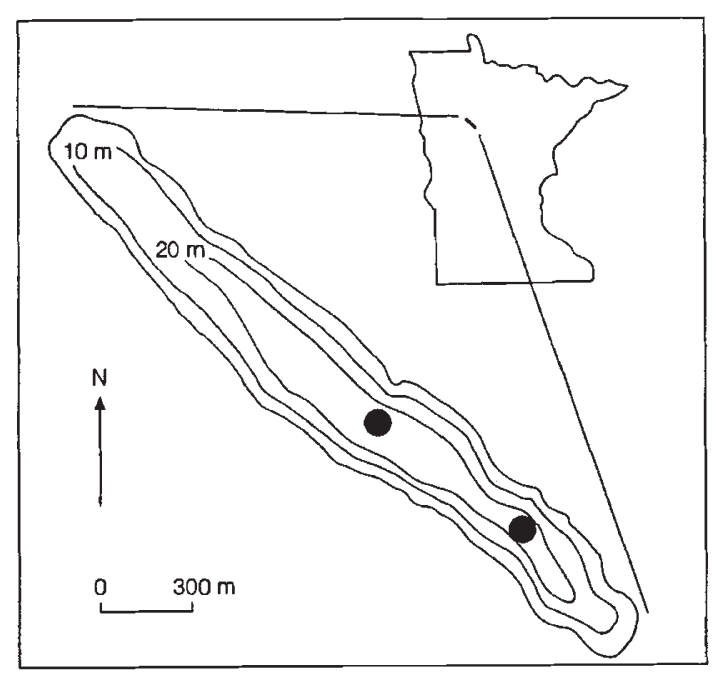

Fig. 1 Long Lake: dark circles indicate the mid-lake and south-east sampling areas. 
Sampling sites were positioned with LORAN C, or with a sextant using three known locations on shore.

Daphnia pulicaria were collected with a closing plankton net $(20 \mathrm{~cm} \times 1 \mathrm{~m}, 63 \mu \mathrm{m}$ mesh $)$ and a removable bucket with a $200 \mu \mathrm{m}$ filter towed vertically $2-5 \mathrm{~m}$ through the backscattering layers. All collections and field observations were made between 10.00 and 16.00 CDT. Field work was conducted from August 7, 1990 to August 2, 1992.

Temperature and dissolved oxygen profiles were obtained with a YSI model 57 oxygen meter. Water transparency profiles were obtained with a Montedoro-Whitney model TMU-IB transmissometer. These limnological parameters were observed at $1 \mathrm{~m}$ intervals on each sampling trip at the north-westerly (midlake) of the two sampling locations.

Daphnia pulicaria samples were returned to the laboratory and either processed within $72 \mathrm{~h}$ or frozen up to six months for later electrophoresis. Freezing involved placing individuals in 96-well micro culture plates with a drop of distilled water. Each loaded micro culture plate was initially placed directly on the cooling coils of a standard upright freezer for rapid freezing and stored at $-19^{\circ} \mathrm{C}$.

Either fresh or thawed D. pulicaria were prepared for electrophoresis by placing individuals directly in Super Z applicator wells (Helena Scientific) and grinding with a spatula in distilled water. Individual D. pulicaria homogenates were applied to cellulose acetate gels and exposed to a $200 \mathrm{~V}$ electric field for 20 min with a Gelman Sciences model PS500 regulated power supply. Electrophoresis chemicals, buffers and stains followed the recipes of Hebert \& Beaton (1989).

The phosphoglucose isomerase $(P G I)$ locus demonstrated sufficient activity and variability to permit subdivision of the $D$. pulicaria population into three single locus genotypes: $F F=$ homozygous fast, $S S=$ homozygous slow and $F S=$ heterozygous. These single locus genotypes will be referred to as clones because we did not observe males in our samples and because the large deviations from Castle-Hardy-Weinberg equilibrium were consistent with a parthenogenetically reproducing population. Each of these single locus clones are more appropriately viewed as aggregations of genotypes that share the same characteristics at the PGI locus. Ross (1996) has screened an additional 28 loci and found additional variation only at the phosphoglucomutase $(P G M)$ locus.

Identification of individuals as $D$. pulicaria was made by comparing both rostrum reticulation pattern (Brandlova et al., 1972) and lactate dehydrogenase $(L D H)$ electromorphs (Cerney \& Hebert,
1993) with those of $D$. pulex collected at Ice House Pond located at the Lake Itasca Biological Station $10 \mathrm{~km}$ south-east of Long Lake. Daphnia pulicaria exhibited an elongate reticulation pattern on the rostrum and a homozygous fast electromorph at the $L D H$ locus compared to the more symmetrical reticulation and a homozygous slow electromorph at the $L D H$ locus of $D$. pulex. Identification to species based on the $L D H$ electromorph that has gone to fixation in $D$. pulicaria was confirmed independently by M. Boileau (pers. comm.).

Data were analysed using log-linear modelling procedures with the statistical package ' $s$ ' on the University of Minnesota's Academic Computing Services UN1X computer. Log-linear techniques were invoked because the response variable (clone frequency) and the cluster of explanatory variables (water depths, locations on the lake and time) were all categorical. Log-linear modelling permitted the examination of main effects as well as higher-order interactions of the explanatory variables that was not possible with more conventional chi-square analysis. Other data were processed with EXCEL software on a Macintosh SE computer and with STATISTIX, SYGRAPH, DESCSCAN and PLOT-1T software on an IBM computer.

\section{Results}

Limnological data (Fig. 2) collected in 1991 indicated that the lake was thermally stratified during the summer months. The epilimnion (warm layer of surface water) thickened from $4 \mathrm{~m}$ in May to $7 \mathrm{~m}$ in August. A thermocline in the metalimnion extended from $5 \mathrm{~m}$ to $12 \mathrm{~m}$ in May and moved deeper over the course of the summer. The hypolimnion (deep cool water) occurred below $12 \mathrm{~m}$ in May and was reduced in size to water deeper than $15 \mathrm{~m}$ in August.

Water transparency measurements (Fig. 2) indicated relatively high phytoplankton concentrations in the metalimnion, especially mid- to late summer 1991. This resulted in a positive heterograde dissolved oxygen profile (Fig. 2) because of excess photosynthesis relative to community respiration at these depths. A qualitative examination of the metalimnetic phytoplankton indicated that a cryptophyte in the genus Chroomonas dominated the algal populations and was presumably largely responsible for the increased levels of dissolved oxygen observed in the metalimnion. Dissolved oxygen levels declined sharply in the hypolimnion late in the summer, resulting in near anoxia in deep water by late August. Limnological conditions were not monitored 


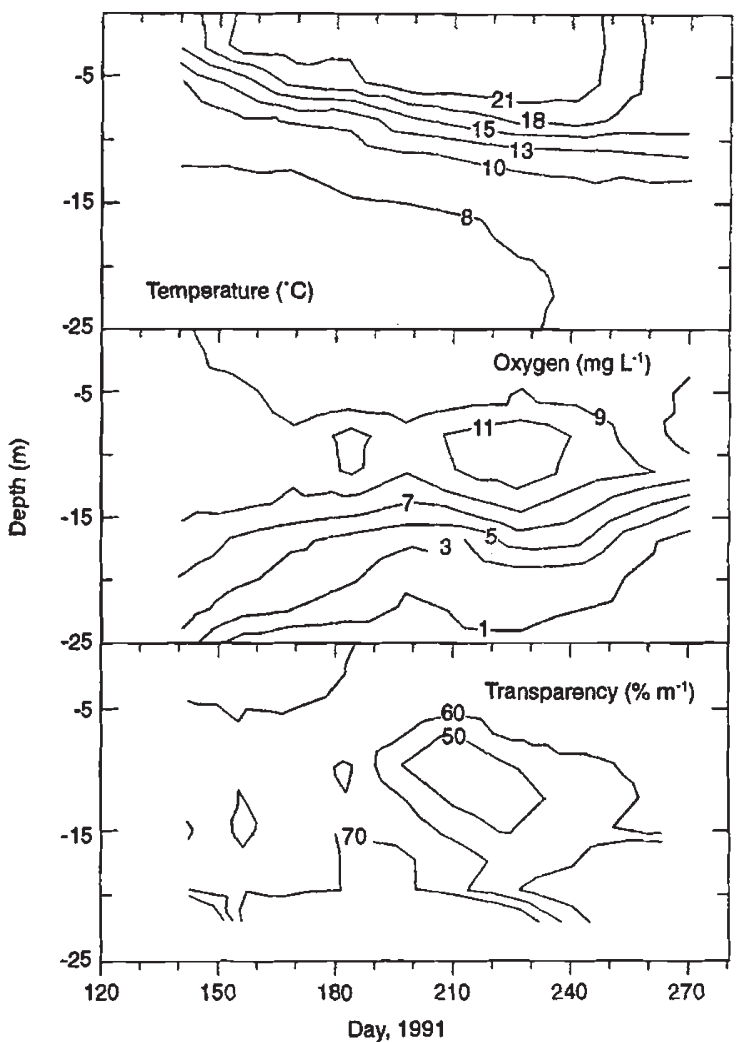

Fig. 2 Water temperature, dissolved oxygen and transparency at the mid-lake sampling site in Long Lake during summer 1991.

in 1990; however, similar conditions were observed in August 1992.

Preliminary lengthwise acoustic transects indicated that major mid-day concentrations of zooplankton were usually found in the south-east two-thirds of the lake and that the vertical distribution was typically concentrated in three layers; an upper layer located in the epilimnion, a middle layer in the metalimnion and upper hypolimnion (this layer will be referred to as the metalimnetic layer) and the lowest layer located deeper in the hypolimnion. A series of acoustic cross-sections made on three occasions across the mid-lake and south-east sampling points (Fig. 3) illustrates the vertical distribution of zooplankton. The graphs accompanying each crosssection show a more quantitative depth profile; the average of five echo returns from the centre of each cross-section at the site where $D$. pulicaria were collected. Although the layers indicating concentrations of zooplankton were not necessarily composed exclusively of $D$. pulicaria, the acoustic profiles indicated separations in the vertical distribution so that each layer could be sampled separately. The rectangles in Fig. 3 show the depth strata where D. pulicaria were collected for genetic analysis. We did not find $D$. pulicaria in the epilimnion during mid-day; epilimnetic layer(s) were composed principally of copepods.

The acoustic cross-sections (Fig. 3) indicated that within the general three-layer framework there was both temporal and spatial variation. For example, on 22 May the zooplankton layers were more clearly defined in the mid-lake sampling area compared to the south-east area. On 8 July, the separation between the layers had become more apparent. By 7 August, zooplankton densities had become much lower in the epilimnion. Zooplankton had virtually disappeared from the deepest portions of the hypolimnion where dissolved oxygen was depleted, resulting in a more compressed distribution between $7 \mathrm{~m}$ and $18 \mathrm{~m}$.

Table 1 presents sample size data organized by calendar and Julian dates, sample locations and sample depths from the summer of 1991. The number of observations decreased in the August hypolimnetic samples as the population densities declined. Daphnia pulicaria were virtually absent from the metalimnion at the south-east location in September.

Four $P G I$ alleles were found in $D$. pulicaria from Long Lake. Alleles were designated $F=$ fast, $M F=$ medium fast, $M=$ medium and $S=$ slow. The rare $M F$ and $M$ alleles were omitted from the analyses.

Early summer samples appeared homogeneous regardless of depth or location. However, by 8 July the proportion of homozygous slow $(S S)$ individuals increased significantly in the hypolimnion at both the mid-lake and south-east locations, whereas proportions of heterozygous $(F S)$ individuals decreased in the hypolimnion (Fig. 4). Much less variability appeared in the proportions of clones in samples from the metalimnion. By late August there appeared to be differences in clone proportions associated with each location. At this time $S S$ individuals made up a larger proportion of the clones in both the metalimnion and hypolimnion at the southeast location. The 104 homozygous fast $(F F)$ individuals were omitted from Fig. 4 because they constituted less than 4 per cent of the sample and because no trend was apparent.

Log-linear modelling of the clone proportions in Fig. 4 (including $F F$ individuals) indicated that all three main effects (date, location and depth) as well as the date-location and date-depth interactions were significant in explaining the proportions of 

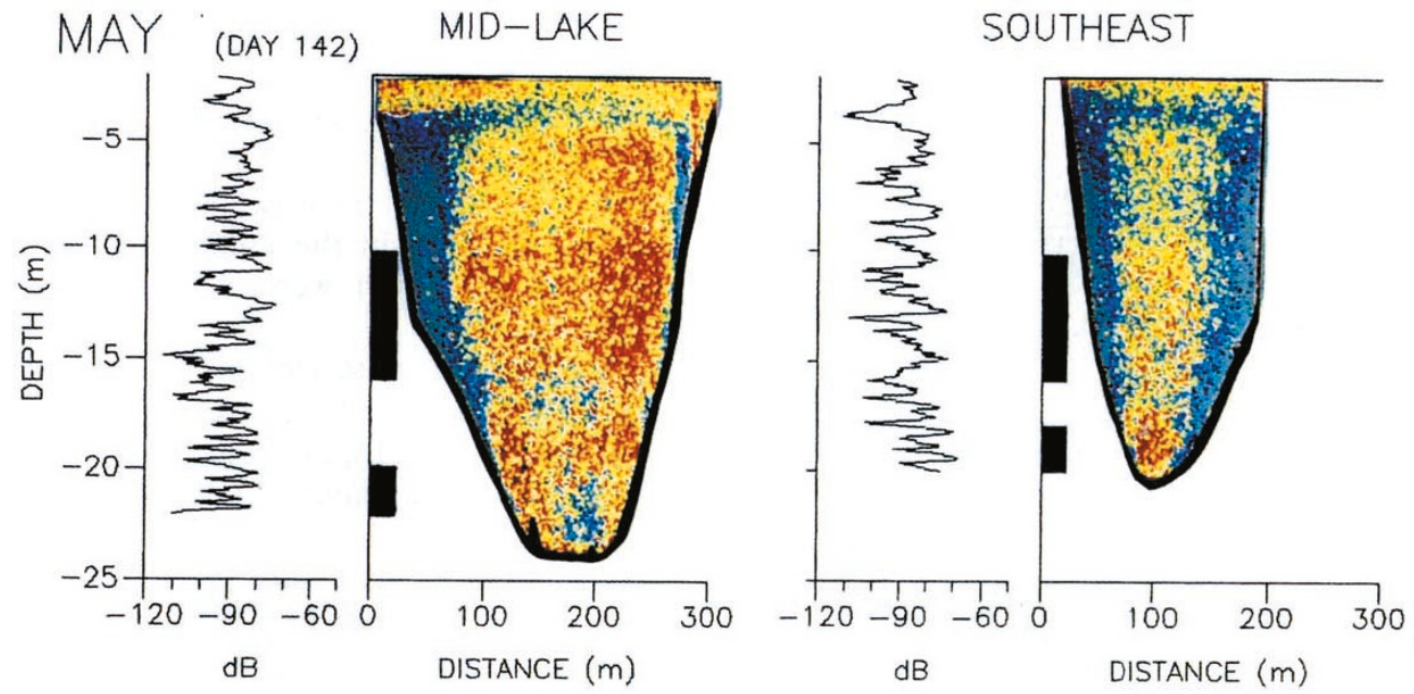

JUL (DAY 189)
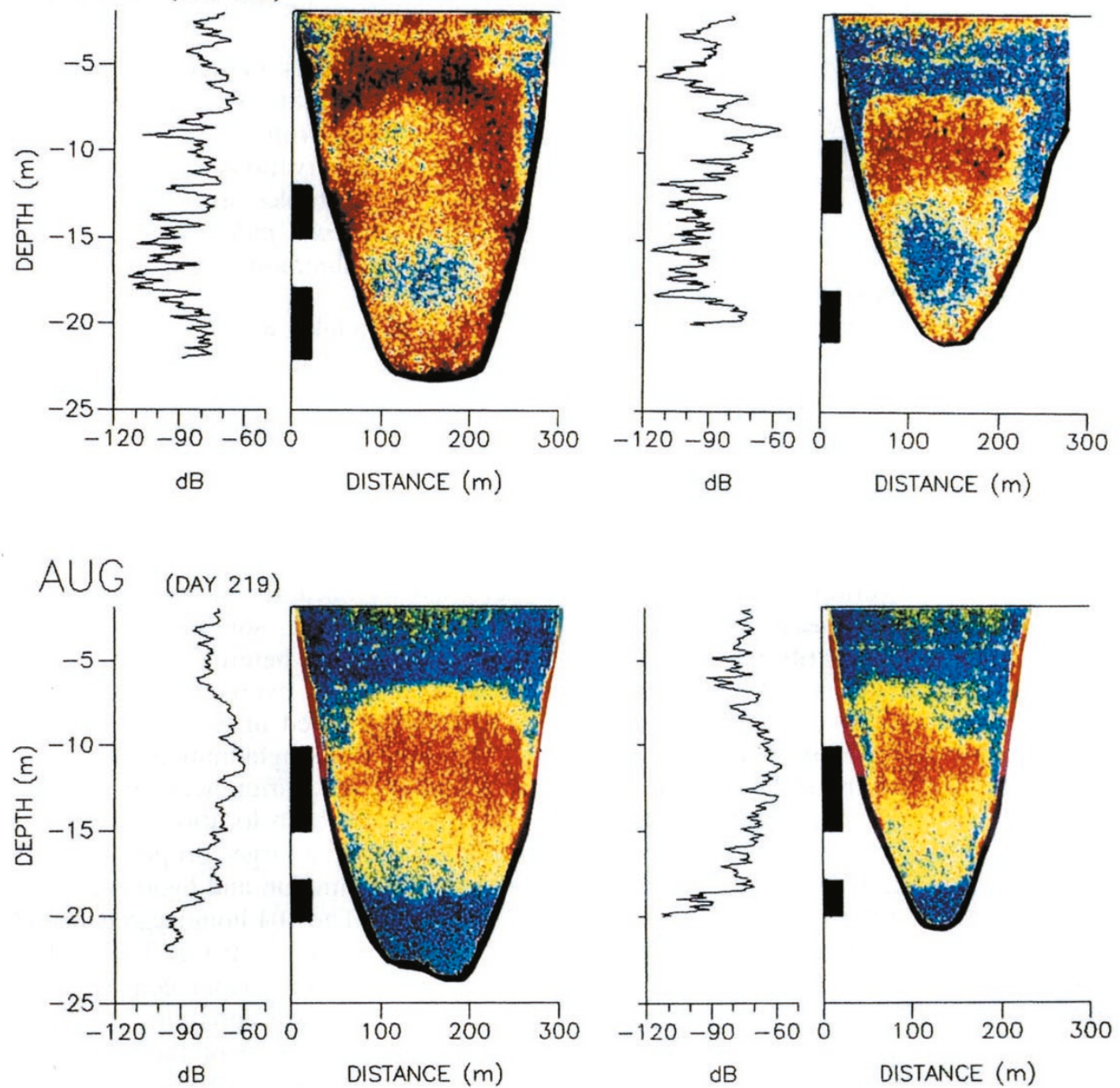

Fig. 3 Acoustic cross-section transects (colour photographs) and averaged sample site echo profiles (line graphs) of mid-lake and south-east sampling areas on 22 May, 8 July and 7 August, 1991. High zooplankton densities are red, moderate densities are yellow and low densities are blue. Acoustic backscattering was measured as volume scattering strength (corrected for depth) and expressed in terms of decibels (dB). 
Table 1 Sample sizes for the single locus $(P G I)$ genotype (= clone) proportions of Daphnia pulicaria in Fig. 4

\begin{tabular}{|c|c|c|c|c|c|c|c|c|c|}
\hline \multirow[b]{2}{*}{ Depth } & \multirow[b]{2}{*}{ Location } & \multicolumn{8}{|c|}{ Day 1991} \\
\hline & & $\begin{array}{l}22 \text { May } \\
(142\end{array}$ & $\begin{array}{l}3 \text { June } \\
154\end{array}$ & $\begin{array}{c}\text { 16 June } \\
167\end{array}$ & $\begin{array}{c}8 \text { July } \\
189\end{array}$ & $\begin{array}{l}23 \text { July } \\
204\end{array}$ & $\begin{array}{l}7 \text { Aug. } \\
219\end{array}$ & $\begin{array}{l}19 \text { Aug. } \\
231\end{array}$ & $\begin{array}{c}20 \mathrm{Sept} \\
263)^{*}\end{array}$ \\
\hline \multirow[t]{2}{*}{ Metalimnion } & South-east & 94 & 96 & 93 & 92 & 96 & 94 & 90 & 0 \\
\hline & Mid-lake & 93 & 90 & 89 & 92 & 91 & 93 & 89 & 94 \\
\hline \multirow[t]{2}{*}{ Hypolimnion } & South-east & 44 & 92 & 88 & 88 & 92 & 59 & 18 & 92 \\
\hline & Mid-lake & 46 & 92 & 93 & 76 & 96 & 32 & 41 & 95 \\
\hline
\end{tabular}

Total: 2530

*Julian dates in parentheses.

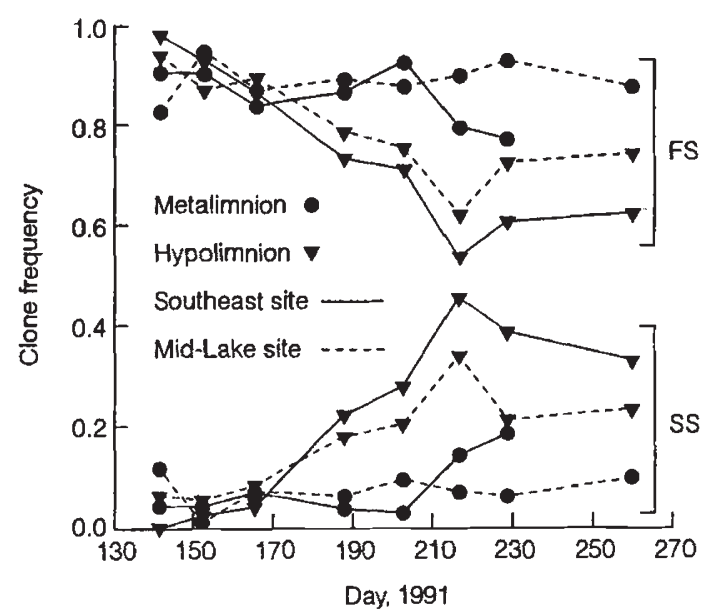

Fig. 4 Relative frequencies of heterozygous $(F S)$ and homozygous slow (SS) Daphnia pulicaria clones in metalimnetic and hypolimnetic samples from mid-lake and south-east sites in Long Lake during the summer 1991. Sample size data are in Table 1.

clones observed over the summer months during 1991. Log-linear results are summarized in Table 2 using Pearson $\chi^{2}$ statistics and deviance values $\left(G^{2}\right)$ for all applicable models, i.e. models with interactions among the explanatory variables included. The only log-linear model that fitted the data $\left(\chi^{2}\right.$; $P \geq 0.05)$ was the second model: [123] [124] [234]. This model states that the response variable [1] (clone frequency) was related to the explanatory variable cluster [234] (date, location and depth) by date, location and the date-location interaction [123]; and independently by date, depth and the date-depth interaction [124]. Additional explanation of the modelling notation is provided at the bottom of Table 2. Examination of the model components (reduction in the $G^{2}$ statistic) revealed that date and depth main effects were greatest; location was less important, although significant, in explaining clone proportions. Further, the date-depth interaction was greater than the date-location interaction in explaining clone proportions during a single summer season.

The frequency of slow $(S)$ alleles at the $P G I$ locus increased over the course of the summer in 1991 in populations from both the metalimnion and the hypolimnion, but the increase was considerably greater in the hypolimnetic population. During the first three sampling dates in May and June the $S$ allele occurred at a frequency of 0.50 in samples of $D$. pulicaria from both the metalimnion and hypolimnion. After a transition period in early July, the proportion of $S$ alleles had changed in late summer to 0.54 in the metalimnion and 0.65 in the hypolimnion.

Examination of clone proportions in early August over a three-year period (Table 3) revealed that the proportions of $S S$ individuals were consistently greater in the hypolimnion at this time of the year. However, variability was observed from year to year and between locations. The proportion of $F F$ individuals decreased from 1990 to 1992 while there was an increasing trend in the proportion of $F S$ and $S S$ individuals. Additionally, there appeared to be a slightly higher proportion of $F S$ individuals and slightly lower proportions of $F F$ and $S S$ individuals at the south-east location.

Log-linear modelling of the multiyear data in Table 3 indicated that all three main effects, depth, location and year, as well as the location-year interaction, were significant in explaining the clone proportions. Log-linear results are summarized in Table 4 for all models that fit the data, i.e. that fulfilled the initial criterion of having an acceptable 
Table 2 Summary of log-linear models applied to the data in Fig. 4

\begin{tabular}{|c|c|c|c|c|c|}
\hline Model & $\begin{array}{c}\text { Pearson } \\
\chi^{2}\end{array}$ & d.f. & $G^{2}$ & $\begin{array}{l}\text { Change in } \\
G^{2} \\
\text { from base }\end{array}$ & $\begin{array}{c}\text { Change in } \\
\text { d.f. } \\
\text { from base }\end{array}$ \\
\hline$[123][124][134][234]$ & 21.29 & 12 & 25.28 & 257.12 & 48 \\
\hline$[123][124][234]$ & 22.39 & 14 & 26.47 & 255.93 & 46 \\
\hline [123] [134] [234] & 58.11 & 26 & 62.17 & 220.23 & 34 \\
\hline$[124][134][234]$ & 42.67 & 26 & 44.04 & 238.36 & 34 \\
\hline [124] [13] [234] & 44.00 & 28 & 49.07 & 233.33 & 32 \\
\hline [123] [14] [234] & 60.04 & 28 & 64.80 & 217.60 & 32 \\
\hline$[134][12][234]$ & 80.00 & 40 & 86.68 & 175.72 & 20 \\
\hline$[124][234]$ & 49.38 & 30 & 55.14 & 227.26 & 30 \\
\hline [123] [234] & 118.01 & 30 & 126.45 & 155.95 & 30 \\
\hline$[134][234]$ & 186.30 & 54 & 210.59 & 71.81 & 6 \\
\hline [12] [13] [14] [234] & 82.86 & 42 & 88.08 & 194.32 & 18 \\
\hline$[12][14][234]$ & 88.75 & 44 & 95.07 & 187.33 & 16 \\
\hline [13] [12] [234] & 138.85 & 44 & 152.98 & 129.42 & 16 \\
\hline [13] [14] [234] & 187.83 & 56 & 212.74 & 69.66 & 4 \\
\hline [12] [234] & 149.48 & 46 & 162.38 & 120.02 & 14 \\
\hline$[14][234]$ & 199.62 & 58 & 220.02 & 62.38 & 2 \\
\hline [13] [234] & 274.36 & 58 & 274.54 & 7.86 & 2 \\
\hline$[1][234]$ & 291.00 & 60 & 282.40 & Base model & \\
\hline
\end{tabular}

$[1] \rightarrow$ clone $=$ response variable; [2] $\rightarrow$ date $=$ explanatory variable; [3] $\rightarrow$ location $=$ explanatory variable; [4] $\rightarrow$ depth $=$ explanatory variable.

Model selected: [123] [124] [234].

Interpretation of the model notation is provided in the following examples: [1] [234] $\rightarrow$ clone proportions were independent of date, location and depth; [12] [234] $\rightarrow$ clone proportions were related only to date; [12] [14] [234] $\rightarrow$ clone proportions were related to date and independently to depth but not location; [124] [234] $\rightarrow$ clone proportions were related to date and depth and the datedepth interaction but not location; [123] [124] [234] $\rightarrow$ clone proportions were related to date, location and the date-location interaction, and independently to date, depth and the date-depth interaction.

Pearson $\chi^{2}$ value $(P \geq 0.05)$. Although several models met this criterion, model selection procedures including the information criterion by itself, information criterion plotted against the number of model parameters, stepwise selection and the principal of parsimony, all converged on the model [12] [134] [234]. This model indicated that the response variable [1] (clone frequency) was related to the explanatory variable cluster [234] (depth, location and year) by depth [12] and independently by location, year and the location-year interaction [134]. Examination of the model components revealed that depth and year effects were greatest in explaining clone frequencies followed to a lesser, although significant, degree by location and a relatively high location-year interaction.

\section{Discussion}

Results from this study indicate that $D$. pulicaria in Long Lake were distributed in two relatively discrete layers during daylight hours, one in the metalimnion and very upper hypolimnion, and the other deeper in the hypolimnion. The change in $D$. pulicaria clonal composition was associated with changing pelagic environmental conditions deep in the hypolimnion. Specifically, an increase in the frequency of homozygous slow $(S S)$ individuals at the $P G I$ locus was associated with oxygen depletion deep in the hypolimnion. The clone frequency remained more constant in the more stable metalimnetic and upper hypolimnetic environment, where phytoplankton photosynthesis produced enough oxygen to more 
than balance demands by respiration. Further, the increased frequencies of the $S S$ clone in the deep hypolimnion by early August appeared to be a repeatable pattern over the three-year study.

Table 3 Proportions of single locus ( $P G I$ ) genotypes ( = clones) from 825 Daphnia pulicaria at two locations and two depths in Long Lake during early August 1990-1992

\begin{tabular}{llccc}
\hline & & \multicolumn{2}{c}{ Depth } \\
\cline { 4 - 5 } Date & \multirow{2}{*}{ Location } & Clones & Metalimnion & Hypolimnion \\
\hline August 7 & Mid-lake & $F F$ & 0.33 & 0.12 \\
1990 & & $F S$ & 0.65 & 0.60 \\
& & $S S$ & 0.02 & 0.28 \\
& & & $(60)$ & $(60)$ \\
& South-east & $F F$ & 0.38 & 0.17 \\
& & $F S$ & 0.60 & 0.80 \\
& & $S S$ & 0.02 & 0.03 \\
August 7 & Mid-lake & $F F$ & 0.02 & $(60)$ \\
1991 & & $F S$ & 0.90 & 0.03 \\
& & $S S$ & 0.08 & 0.63 \\
& & & $(93)$ & $(32)$ \\
& South-east & $F F$ & 0.05 & 0.00 \\
& & $F S$ & 0.80 & 0.54 \\
& & $S S$ & 0.15 & 0.46 \\
August 2 & Mid-lake & $F F$ & 0.03 & $(59)$ \\
1992 & & $F S$ & 0.81 & 0.07 \\
& & $S S$ & 0.16 & 0.56 \\
& & & $(68)$ & 0.37 \\
& South-east & $F F$ & 0.02 & $(84)$ \\
& & $F S$ & 0.92 & 0.00 \\
& & $S S$ & 0.06 & 0.23 \\
& & $(95)$ & $(60)$ \\
\hline
\end{tabular}

The sample size from each depth at each location is in parentheses.
In many circumstances the most conspicuous environmental changes in small- to medium-sized freshwater lakes correlate with depth, especially during the period of summer thermal stratification. Progressive oxygen depletion during the summer months in the hypolimnion of stratified lakes has been well documented and has been attributed principally to oxidation of organic matter (Hutchinson, 1957). Middle to late summer hypolimnetic oxygen deficits occur annually in the pelagic environment at Long Lake (Megard, 1968; Ross, 1996).

The hypolimnion at Long Lake was characterized by lower values for both dissolved oxygen and temperature compared to the metalimnion. Both parameters have been shown to affect Daphnia clone composition in laboratory experiments. Weider \& Lampert (1985) reported that certain clones of $D$. pulex produced less haemoglobin in response to a reduced oxygen environment and were therefore less tolerant of low oxygen conditions than clones that produced more haemoglobin. Weider (1985) reported that competitive interactions between clones of $D$. pulex were influenced by oxygen concentration. LaBerge \& Hann (1990) also found significant differences in $D$. pulex clonal tolerance to low oxygen concentrations and that this difference was related to clones differing at the haemoglobin locus. Their results also suggested clone-specific responses to temperature. Carvalho (1987) found marked thermal differentiation among clones of $\dot{D}$. magna and reported that seasonal changes in clone frequency were related to differences in thermal tolerance of specific genotypes.

We believe the $D$. pulicaria response observed deep in the hypolimnion of Long Lake was caused primarily by oxygen depletion. Clonal proportions did not vary with depth in early summer samples when oxygen concentrations were more uniformly

Table 4 Summary of log-linear models applied to the data in Table 3

\begin{tabular}{lrrrcc}
\hline & $\begin{array}{c}\text { Pearson } \\
\chi^{2}\end{array}$ & d.f. & \multicolumn{1}{c}{$G^{2}$} & $\begin{array}{c}\text { Change in } \\
G^{2} \\
\text { from base }\end{array}$ & $\begin{array}{c}\text { Change in } \\
\text { d.f. } \\
\text { from base }\end{array}$ \\
\hline [123] [124] [134] [234] & 7.66 & 4 & 7.62 & 209.47 & 18 \\
[124] [134] [234] & 9.20 & 6 & 8.96 & 208.13 & 16 \\
[123] [134] [234] & 12.83 & 8 & 13.79 & 203.30 & 14 \\
[124] [234] & 16.07 & 9 & 16.47 & 200.62 & 13 \\
[12] [134] [234] & $\mathbf{1 6 . 5 3}$ & $\mathbf{1 0}$ & $\mathbf{1 6 . 6 4}$ & $\mathbf{2 0 0 . 4 5}$ & $\mathbf{1 2}$ \\
[1] [234] & 234.59 & 22 & 217.09 & Base Model & \\
\hline
\end{tabular}

[1] $\rightarrow$ clone $=$ response variable; [2] $\rightarrow$ depth $=$ explanatory variable; [3] $\rightarrow$ location $=$ explanatory variable; $[4] \rightarrow$ year $=$ explanatory variable.

Model selected: [12] [134] [234]. 
distributed even though the lake was thermally stratified. Most of the above cited literature documented clone-specific responses to temperature and/or oxygen in 30 days or less. It was not until early to mid-July that proportions of the $S S$ clone increased deep in the hypolimnion, corresponding to the onset of oxygen depletion in the physiologically significant range of $1-3 \mathrm{mg} / \mathrm{L}$ (Kring \& O'Brien, 1976). Further, the pattern of a progressive increase in $S S$ clone frequency during July and August corresponded to a simultaneous progressive decline in oxygen concentration deep in the hypolimnion, whereas the thermal environment remained relatively stable.

Although depth-related changes in summer clone composition clearly appeared to dominate the data, horizontal location was found to have a significant, albeit lesser, effect on clone frequency. This secondary effect was observed both within a single summer season (1991) and among years in early August. Additionally, there was a significant reduction in $F F$ clone frequency after 1990 . However, given the horizontal and annual differences, depth, time and the time-depth interaction were found to explain the largest proportion of the changes in clone frequencies.

Our observations that most changes of clone frequency occurred in the hypolimnion during a period of oxygen depletion, provide further support for the concept that spatial and temporal gradients can obviate competitive exclusion and promote the high degree of genetic variation and clonal coexistence that Hebert \& Crease (1980) found in parthenogenetically reproducing cladocerans. As LaBerge \& Hann (1990) noted, patterns of clone frequency may develop as a consequence of genotypically distinct clones preferentially inhabiting those regions of a pond or lake according to genetically based physiological tolerances. Our observation that clone frequency changes were limited to a changing hypolimnetic environment but that clone frequencies were relatively constant in a more stable metalimnetic environment also supports the concept of Carvalho \& Crisp (1987) that a population may consist of a mixture of ecological generalists and seasonal specialists.

Although many studies have observed nonrandom temporal distribution of Daphnia clones, it has been difficult to delineate patterns and to identify environmental conditions that may have produced them. The elusive nature of temporal patterns in Daphnia clone structure can be attributed to the complexity of the habitats. Only Carvalho \& Crisp (1987) have been able to demonstrate repeatable temporal patterns. However, they were working in a small (0.1 sq. $\mathrm{km})$, shallow (1.2 $\mathrm{m}$ max. depth) environment. More complex environments such Big Smith Pond (6 m max. depth) that undergo seasonal vertical stratification (Weider, 1984, 1985) provide confounding vertical and horizontal gradients that can obscure subtle temporal patterns of clone succession which may be restricted to particular areas of aquatic habitats.

As Wieder (1985) noted, both spatial and temporal components need to be examined simultaneously in a complex environment in order to provide a more thorough understanding of mechanisms that influence genetic patterns. We attempted to meet these criteria in a deep, but relatively simple, single basin lake system. To the extent that we found a temporal pattern in clone composition, we believe two elements were critical. First, the ability precisely to locate and sample persistent vertical layers of zooplankton with acoustic methods in a heterogeneous and dynamic environment was fundamental to this study. Sampling at $1 \mathrm{~m}$ intervals, Muller \& Seitz (1993) reported that clonal groups were not homogeneously distributed with depth; however, previous studies such as those reported by Mort \& Wolf (1985) and Jacobs (1990) used vertical tows, thus combining Daphnia samples from all depths. The integration of Daphnia from more than one vertical habitat could have obscured subtle temporal patterns in these studies. We were able to detect aggregations of zooplankton with sonar before we selected sampling depths. Secondly, the power afforded by log-linear modelling to analyse the effects, relative magnitudes and interactions of the temporal and spatial explanatory variables on clone frequencies was instrumental in discriminating temporal variation from spatial variation and elucidating a temporal pattern in the hypolimnion.

Two nonmutually exclusive mechanisms could account for the increase in the $S$ allele proportions in $D$. pulicaria populations in the hypolimnion. An increase in fitness of individuals with the $S$ allele in the hypolimnion could explain the increase. An alternative is that the behaviour of $S S$ individuals was different from that of other clones. These individuals may select different habitats. Conceivably these individuals could have moved from the dense aggregations in the metalimnion to the deeper layer where densities were lower. Our only estimates of population density are from acoustic profiles that cannot discriminate between $D$. pulicaria and other zooplankton species. Therefore, we cannot decide with any certainty the relative contributions of the microevolution hypothesis vs. the behaviour 
hypothesis. However, because the proportions of the $S$ allele increased in both layers during summer, we believe that the increase in the proportions of the $S$ allele in $D$. pulicaria in the hypolimnion was more likely a result of a change in allele frequency than a result of a differential preference in habitat.

\section{Acknowledgements}

We thank Ming Ruan, Judy Haroldson, Adriane Ross, Andy Ross and students of the ecology and ecological genetics courses at the Lake Itasca Biological Station for field and laboratory assistance. Kinley Larntz provided statistical assistance. David Czarnecki provided assistance with phytoplankton identification, reviewed the manuscript and was a constant source of encouragement. William Schmid and Donald Siniff made many helpful suggestions throughout the project. This research was supported by grants from the Sigerfoos fund, Dayton and Wilke Funds, Sigma Xi and the Lake Itasca Biological Station.

\section{References}

BRANDLOVA, J.; BRANDL, z. AND FERNANDO, C. H. 1972. The Cladocera of Ontario with remarks on some species and distribution. Can. J. Zool., 50, 1373-1403.

CARVAlHo, G. R. 1987. The clonal ecology of Daphnia magna (Crustacae: Cladocera). II. Thermal differentiation among seasonal clones. J. Anim. Ecol., 56, 469-478.

CARVAlHo, G. R. AND CRISP, D. J. 1987. The clonal ecology of Daphnia magna (Crustacae: Cladocera). I. Temporal changes in the clonal structure of a natural population. J. Anim. Ecol, , 56, 453-468.

CERNY, M. AND HEBERT, P. D. N. 1993. Genetic diversity and breeding system variation in Daphnia pulicaria from North American lakes. Heredity, 71, 497-507.

HEBERT, P. D. N. 1974. Enzyme variability in natural populations of Daphnia magna II. Genotypic frequencies in permanent populations. Genetics, 77, 323-334.

HEBERT, P. D. N. 1978. The population biology of Daphnia (Crustacea, Daphnidae). Biol. Rev, 53, 387-426.

HEBERT, P. D. N. AND BEATON, M. J. 1989. Methodologies for Allozyme Analysis Using Cellulose Acetate Electrophoresis. Helena Laboratories, Beaumont, TX.

HEBERT, P. D. N. AND CREASE, T. J. 1980 . Clonal coexistence in Daphnia pulex (Leydig): another planktonic paradox. Science, 207, 1363-1365.

HEBERT, P. D. N. AND WARD, R. D. 1976. Enzyme variability in natural populations of Daphnia magna. Ecological differention and frequency changes of genotypes at Audley End. Heredity, 36, 331-341.

hutchinson, G. E. 1957. A Treatise on Limnology, vol. 1. John Wiley and Sons, New York.
JACOBS, J. 1990. Microevolution in predominantly clonal populations of pelagic Daphnia (Crustacae: Phyllopoda): Selection, exchange, and sex. J. Evol. Biol., 3, 257-282.

KRING, R. L. AND O'BRIEN, w. J. 1976. Effect of varying oxygen concentrations on the filtering rate of Daphnia pulex. Ecology, 57, 808-814.

LABERGE, s. AND HANN, B. J. 1990. Acute temperature and oxygen stress among genotypes of Daphnia pulex and Simocephalus vetulus (Cladocera, Daphiniidae) in relation to environmental conditions. Can. J. Zool., 68, 2257-2263.

LYNCH, M. 1983. Ecological genetics of Daphnia pulex. Evolution, 37, 358-374.

LYNCH, M. 1984. The genetic structure of a cyclical parthenogen. Evolution, 38, 186-203.

MEgARD, R. O. 1967. Limnology, Primary Productivity, and Carbonate Sedimentation of Minnesota Lakes. Limnological Research Center, University of Minnesota. Interim Report no. 1.

MEgArD, R. O. 1968. Planktonic Photosynthesis and the Environment of Calcium Carbonate Deposition in Lakes. Limnological Research Center, University of Minnesota. Interim Report no. 2.

MEgARD, R. O., PEARSON, K. A. AND LARSEN, D. A. 1989. A microprocessor based sonar data acquisition system for fish and plankton research. Proc. Inst. Acoustics Symposium (Edinburgh), Vol. 11, pp. 141-148.

MORT, M. A. AND WOLF, H. G. 1985. Enzyme variability in large-lake Daphnia populations. Heredity, 55, 27-36.

MOYLE, P. B. 1969. Ecology of the Fishes of a Minnesota Lake with Special Reference to the Cyprinidae. Ph.D. thesis, University of Minnesota.

MULLER, J. AND SEITZ, A. 1993. Habitat partitioning and differential vertical migration of some Daphnia genotypes in a lake. Arch. Hydrobiol. Beith., 39, 167-174.

Ross, M. J. 1996. Distribution, Behavior, Reproduction and Physiology of clones of Daphnia pulicaria in a Single Basin Fresh Water Lake. Ph.D. thesis, University of Minnesota.

SCHMID, w. D. 1965. Distribution of aquatic vegetation as measured by line-intercept with SCUBA. Ecology, 46, $816-823$.

WEIDER, L. J. 1984. Spatial heterogeneity of Daphnia genotypes: Vertical migration and habitat partitioning. Limnol. Oceanogr, 29, 225-235.

weIDER, L, J. 1985. Spatial and temporal genetic heterogeneity in a natural Daphnia population. J. Plankton Res., 7, 101-123.

WEIDER, L. J. 1989. Spatial heterogeneity and clonal structure in Arctic populations of apomictic Daphnia. Ecology, 70, 1405-1413.

WEIDER, L. J. AND HEBERT, P. D. N. 1987a. Microgeographic genetic heterogeneity of melanic Daphnia pulex at a low-Arctic site. Heredity, 58, 391-399.

WEIDER, L. J. AND HEBERT, P. D. N. 1987b. Ecological and physiological differentiation among low-Arctic clones of Daphnia pulex. Ecology, 68, 188-198. 
WEIDER, L. J. AND LAMPERT, w. 1985. Differential response of Daphnia genotypes to oxygen stress: respiration rates, hemoglobin content and low-oxygen tolerance. Oecologia, 65, 487-491.

yOUNG, J. P. W. 1979a. Enzyme polymorphism and cyclic parthenogenesis in Daphnia magna. I. Selection and clonal diversity. Genetics, 92, 953-970.

younG, J. P. w. 1979b. Enzyme polymorphism and cyclic parthenogenesis in Daphnia magna. II. Heterosis following sexual reproduction. Genetics, 92, 971-982. 